\title{
Enrollment Projection Using Markov Chains: Detecting Leaky Pipes and the Bulge in the Boa
}

Rex Gandy, Lynne Crosby, Andrew Luna, Daniel Kasper, and Sherry Kendrick

\author{
About the Authors \\ The authors are with Austin Peay State University.
}

\begin{abstract}
While Markov chains are widely used in business and industry, they are used within higher education only sporadically. Furthermore, when used to predict enrollment progression, most of these models use student level as the classification variable. This study uses grouped earned student credit hours to track the movement of students from one academic term to the other to better identify where students enter or leave the institution. Results from this study indicate a high level of predictability from one year to the next. In addition, the use of the credit hour flow matrix can aid administrators in identifying trends and anomalies within the institution's enrollment management process.
\end{abstract}

Keywords: Markov chains, enrollment projections, enrollment management, enrollment trends, enrollment

The AIR Professional File, Fall 2019 Article 147 https://doi.org/10.34315/apf1472019

(c) Copyright 2019, Association for Institutional Research 


\section{INTRODUCTION}

The current challenges facing higher education administrators create myriad reasons to find a crystal ball of sorts to effectively forecast enrollments, predict how many current students will stay at the institution, forecast new students, and adequately estimate revenues. These challenges have become only more pressing in recent years.

More than 20 years ago, when public college and university revenues were ample, administrators were not readily concerned about the future of college enrollments or student persistence. State appropriations were healthy and usually made up more than half of an institution's revenue source. Moreover, with lower tuition more students could afford to obtain a degree without going into significant financial debt (Coomes, 2000).

The costs to run higher education have skyrocketed, however, causing today's institutions to seek scarce resources within an ever-diminishing financial pool. As states tackle other pressing issues such as infrastructure, entitlements, and prisons, the amount they give to higher education naturally wanes. Decreased state revenue, therefore, compels institutions to increase tuition to make up the difference. According to Seltzer (2017), for every $\$ 1,000$ cut from per student state and local appropriations, the average student can be expected to pay $\$ 257$ more per year in tuition and fees. He further notes that this rate is rising.

In addition to decreases in state revenues, higher education administrators are under increasing pressure to be accountable to federal and state governments as well as to regional and disciplinebased accreditors. This accountability is increasingly seen in tougher reporting standards, outcomes- based funding formulae, and mandated student achievement thresholds.

The closest resource to a crystal ball available to administrators is a set of mathematical prediction tools. These prediction tools range from simple formulae contained in spreadsheets to much more complicated regression, autoregressive integrated moving average (ARIMA), and econometric time series models.

According to Day (1997), current predictive tools that are statistically based rely on the institution's ability to access and manipulate large datasets and individual student-record data. While morecomplicated statistical models incorporate variables such as tuition cost, high school graduate numbers, economic factors, and labor-market demand, other models look more specifically at institutional indicators such as high school grade point averages of entering freshmen, as well as the retention, progression, and graduation rates of students.

One such model, the Markov chain, has been relatively underutilized as an enrollment projection tool in higher education. When used properly, however, it can aid institutions in determining progression of students. Specifically, Markov chains are unique from more-traditional ARIMA and regression prediction tools in that the following is true:

1| Markov chains can give accurate enrollment predictions with only the previous year's data. These predictions can be helpful when large longitudinal databases are not available.

2| They can generate predictions on segments of a group of students rather than on the entire population. Other models often require the use of the entire population. 
3| The almost intuitive nature of the Markov chain lends well to changes in student flow characteristics that often cannot be explained by a complex statistical formula.

Moreover, Markov chains might be particularly helpful in determining progression of students during benchmark years when enrollments vary significantly due to state mandates and policies, or due to institutional changes in admission standards. The purpose of this study is to show how a Southeastern, masters-level (Larger Programs) public institution utilized the unique properties of this model to create a tool to better understand credit hour flow and student persistence.

\section{Enrollment Management's Problem with Leaky Pipes and the Bulge in the Boa}

While enrollment management has clearly evolved since the inception of the field of enrollment management in the 1970s, some fundamental processes have essentially stayed the same. Institutions have always wanted to attract the right students who fit well within the institution's role, scope, and mission. Once matriculated into the institution, there is also a strong desire for students to adequately progress through their program and graduate within a reasonable amount of time (Hossler, 1984). As enrollment management developed through time, however, administrators became increasingly aware that college-age students were more difficult to enroll, higher tuition was causing some students to forgo their degree, and institutional loyalty was waning as students transferred to similar or different institutions. Furthermore, institutions have seen an increasing number of students who are not fully prepared for the rigors of college work, putting greater enrollment strain on institutions (Johnson, 2000).
After more than 40 years of enrollment management within higher education, it is not surprising that metaphorical associations have entered the lexicon of the profession as administrators try to better understand and predict student matriculation, persistence, and graduation. For instance, Ewell (1985), referred to students progressing and moving throughout their program as student flow, while Clagett (1991) discussed following the flow of student cohorts through to graduation. Luna (1999) used the concept of student flow to explain the various pathways by which the institution may retain students, and Torraco and Hamilton (2013) discussed the student flow of selected groups of minority students. Furthermore, many software companies have exploited the student flow metaphor to describe use of data to identify areas where leakage is present in student flow pipelines. It is easy, then, to see how the management of student retention can be associated with a pipeline and how administrators are busy trying to plug the leaks.

Markov chains are uniquely suited to identifying these leaks because they can model student flow as a set of transitions between several states, much like a set of pipes with various inflows, outflows, and interconnections. In addition to using the model to project enrollments, it is also possible to observe from year to year where students enter the absorbed state (i.e., do not return to the institution). Leakage within the student credit hour $(\mathrm{SCH})$ flow pipeline occurs when students withdraw or stop out due to reasons that are academic, nonacademic, or both. If the model can isolate where the major leaks occur, the institution can identify causes and work to retain and maintain the flow of students within the pipeline. These leaks in the student flow pipeline can be detected and monitored from term to term so that the institution can develop strategies to maintain a healthier flow. 
Another colorful bit of jargon among enrollment management professionals is the idea of bulging enrollments. For example, Fallows and Ganeshananthan (2004) use the term "bulging of enrollments" to describe a significantly larger share of students needing financial aid or when, due to rising tuition costs, students bulge into less-expensive 2-year colleges. Herron (1988) uses the term "bulge in the boa" to define instances of oversupply in student populations quickly entering the student flow pipeline, much as a boa constrictor swallows a large meal. Liljegren and Saks (2017) added that these bulges can significantly affect higher education and its future. These bulges occur when large groups of students suddenly enter higher education, putting a strain on the student flow pipeline. As the bulge dissipates, its effects may remain, and it may redefine student flow for the future. With Markov chain models, institutions can monitor these bulges in the system so that they can address issues such as course offerings and instructor availability.

\section{Markov Chains and Higher Education}

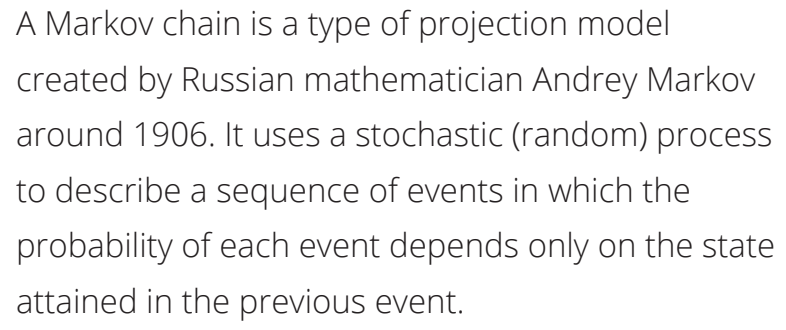

The Markov chain is a stochastic rather than a deterministic model. Unlike a deterministic process where the output of the model is fully determined by the parameter values and by sets of previous states of these values, a stochastic process possesses inherent randomness: the same set of parameter values and initial conditions can lead to different outputs.
Take, for example, the scenario of an individual returning home from work. In a deterministic process, there is only one route (Route A) from work to home, and the amount of time to get home depends only on the variable speed of the driver. In a stochastic process, the individual will have multiple routes (Routes A, B, and C) from which to choose, and each of the routes intersects the other routes at various points. The randomness of the process occurs when the individual combines routes to go home, if she makes the choices at each intersection randomly. For example, the driver may take Route $\mathrm{A}$ part of the time, followed by Route $C$, then Route $B$, and back to Route A again, or take some completely different path. There are many random possibilities the individual may take to get home, leading to a variety of possible driving times.

Markov chains utilize transition matrices that represent the probabilities of transitioning from each possible state to each other possible state. These states can be absorbing or nonabsorbing: nonabsorbing states allow future transitions to other states while absorbing states do not.

Markov chains have been widely and successfully used in business applications, from predicting sales and stock prices to personnel planning and running machines. Markov chains also have been used in higher education, albeit with much less frequency.

In most studies where Markov chains were used in enrollment management, the various transitional states were categorized either by student classification or by other simpler dichotomous measures. Given the strength of the Markovian stochastic process in generating student flow probabilities using data only from the previous year, the process of classifying students into other kinds of states could be appealing. Such states 
could include SCHs, student debt, and (on a more systemwide level) the transitioning from one institution or program to another. The possibilities are diverse.

One of the first to use Markov chains in determining enrollment projections was Oliver (1968) when he compared Markov chains to the much more established use (at that time) of grade progression ratios to predict enrollments at the University of California. According to Oliver's study, enrollment forecasting made a prediction on the basis of historical information on past enrollment and admission trends. In determining a stochastic process, Oliver demonstrated that the fraction of students who leave one grade level (class status) $i$ and progress to class status $j$ is a fraction $p_{i j}$; that progress could also be time dependent. These fractions $p_{i j}$ can also be interpreted as random transition probabilities. He determined that the process allowed for contributions in one grade level that were identified by their origins, such as prior grade level, returning to the same grade level, and new admissions (Oliver, 1968).

According to Hopkins and Massy (1981), the use of Markov chains allows the researcher to observe the flow of students from one classification level (i.e., freshman, sophomore, junior, senior) to the next class level. The chain also incorporates students who stay at the same class level from one year to the next. Therefore, the Markov chain for class level, as studied by Hopkins and Massy, can be described as follows:

1| The number of students in class level $i$ who progress to class level $j$

2| The number of students in class level $i$ who stay in the same level
3| The number of students who leave the institution (drop out, stop out, or graduate)

Similarly, Borden and Dalphin (1998) used Markov chains to develop a 1-year enrollment transition matrix to track how students of each class level progressed. The authors found that unique Markov chain models were valuable in measuring student progression without having to rely on 6-year graduation rate models, which could be ineffective due to the large time lags. Specifically, the model was built around a transition matrix where student flow was tracked from one year to the next, and the rates of transition from four nonabsorption states (i.e., freshman to sophomore) were placed into a matrix that was separate from the two absorption states (i.e., drop out, graduate).

Using the percentages in the two matrices, those students who continue in nonabsorption states were processed through the matrix using the established rates of transition until, asymptotically, all students reach the final absorption state.

Additionally, Borden and Dalphin (1998) developed discrete Markov chain processes to simulate the effect of changes in student body profile on graduation rates. In these models, the authors incorporated credit-load and grade performance categories. Their results indicated that, while there was a strong association between grade performance and persistence, it took very large changes in levels of student performance to impact retention and graduation rates modestly.

In a more narrowly focused study, Gagne (2015) used Markov chains to predict how English Language Institute (ELI) students progressed through science, technology, engineering, and math (STEM) programs. Specifically, the model 
created transitional (nonabsorbing) states based on classification level and three absorbing states to include those students who left the institution, those who graduated from a STEM program, or those who graduated from a non-STEM program. Findings from their study indicated that the ELI students tended to progress at a higher rate than non-ELI students in STEM programs, and that ELI students who repeated the freshman year were more likely to repeat again than they were to transition to the sophomore year.

Correspondingly, a study by Pierre and Silver (2016) used Markov chain models to determine the length of time it took students to graduate from their institutions. As with previous studies, students were divided into nonabsorbing transitional states (i.e., freshman, sophomore, junior, senior) and absorbing states (i.e., graduate, nonreturning). Using the Markovian property, the future probability of transitioning from one state to another depended only on the present state of the process and was not influenced by its history. The study found that it took 5.9 years for a freshman to graduate and 4.5 years for a sophomore to graduate from the institution.

Brezavšček, Bach, and Baggia (2017) successfully used Markov chain models to investigate the pattern of students' enrollment and academic performance at a Slovenian institution of higher education. The model contained five transient or nonabsorbing states and two absorbing states. The authors used student records for a total of eight consecutive academic seasons, and estimated the students' progression toward the next stage of the program. From those transition percentages they were able to obtain progression, graduation, and withdrawal probabilities.

As mentioned earlier, most Markov chain models involving enrollment management and prediction use student classification to create the various states of the model. Using student classification in model specification, however, could create states that are overly broad in nature since, at most semester-based colleges and universities, student classification varies by 30 hours.

Ewell (1985), who also used Markov chains to predict college enrollments, noted two limitations of the models. First, because the estimation of the probabilities rests on historical data, Markov chains may be sensitive to when the data were collected. This could be especially true with significant enrollment gains or declines from one year to the next. Second, according to Ewell, different subpopulations may behave in different ways, thus necessitating the need to disaggregate into smaller groupings.

However, the Markov chain's attributes may allow a unique ability to detect the leaks and bulges. Because this type of projection model uses the stochastic process to describe a sequence of events in which the probability of each event depends only on the state attained in the previous event, changes to student flow are immediate and are not subject to potentially skewed results of the past. In short, the limitations mentioned by Ewell (1985) can be utilized when building the student flow matrices to detect significant shifts in enrollment and to determine which groups of students are leaving the institution at a higher rate.

\section{METHODOLOGY}

The current study used Markov chains to predict Fall enrollment at a Southeastern, masters-level (Larger Programs) public institution based on annual Fall semester enrollment for degree-seeking 
undergraduates. The process involved obtaining data from the institution's student information system and separating students into groupings based on their cumulative SCHs earned. Student flow was measured from Fall of year $i$ to Fall of year i+1 based on whether students stayed within their credit hour category, moved into another credit hour category, or did not enroll at the institution. These student flow changes for each category were then summed and applied to year $i+2$ as a prediction of enrollment.

Within the model, at a given point in time each student has a particular state, and each student is treated as having a particular probability of transitioning to each other state or staying within the same state. Most of these states are based on the number of SCH the student has accumulated (i.e., the $\mathrm{SCH}$ category). Because the $\mathrm{SCH}$ category of a student was determined by the number of cumulative SCHs a student earned, most of the credit hour flow scenarios included students advancing to a higher credit hour category or students withdrawing or graduating. While it is rare for a student to move from a particular credit hour category to a lower category, it can happen through the transfer process when, after the student has enrolled, the current institution does not accept certain SCHs from the former institution.

The characteristic that makes this model a Markov chain is the fact that a given student's transition probabilities between states are assumed to depend only on that student's current state and not on any of the student's previous states. This is a simplifying assumption that allows all students within a given state to be treated similarly regardless of their histories. Otherwise, the model would become much more complicated and difficult to apply.
The main parameters of the model are estimates of these transition probabilities. These transition probabilities are estimated by calculating the fractions of students that transitioned from each state to each other state relative to the number of students initially in that state in past years' enrollment data. The other parameters of the model are the fractions of new incoming students by credit hour category. The total number of new incoming students is assumed to be fixed, thus the estimated number of incoming students by credit hour category follows from these fractions.

The model process is recursive in that predictions for Fall $X$ are produced from the enrollment data from Fall $X-2$ and Fall $X-1$ and the subsequent flow rates from Fall X-2 to Fall X-1.

We can now describe the basic assumptions that we used to construct the predictive models:

1| Each model models flow from one year to the next and is named accordingly. For example, Fall 2013 to Fall 2014 is known as the 13_14 Model and is based on the starting data for Fall 2013 and the new student data from Fall 2014.

21 As the model is applied, the output headcount by $\mathrm{SCH}$ level for the $(i+1)$ th year becomes the input headcount for the next iteration of the model.

3| When the model is applied to a future year, the total number of new students is assumed to be constant and the same as the number of new students for the $(i+1)$ th year. The distribution of new students by $\mathrm{SCH}$ level is also assumed to be constant.

4| When the model is applied to a future year, it is assumed that the fractional student loss and fractional student continuation ratios are fixed by SCH level. 
5| When the model is applied to a future year it is assumed that the fractional flow from SCH level to $\mathrm{SCH}$ level is the same as for the year used to construct the model.

The model divides the undergraduates into 24 6-SCH groupings. This method uses historic ratios of $\mathrm{SCH}$ student subsets gathered from the student information system to predict future Fall headcounts.

The 6-SCH groupings used in this model are individually less broad than the more familiar student classification levels. However, it is possible to aggregate the 6-SCH bins into a version of these student levels, which we define as

- Freshmen: $\leq 30 \mathrm{SCH}$

- Sophomore: $>30 \mathrm{SCH}$ and $\leq 60 \mathrm{SCH}$

- Junior: $>60 \mathrm{SCH}$ and $\leq 90 \mathrm{SCH}$

- Senior: $>90 \mathrm{SCH}$

Note that these classification-level definitions do not exactly match the institution's definitions. In using $\mathrm{SCH}$ groupings, the enrollment pipeline may be much more finely observed and enrollment patterns among students may be more precisely distinguished. While it is the goal of this study to develop a model to predict the coming Fall enrollment once the previous Fall enrollment is known, the model will not address enrollment by major, academic department, or college.

\section{MODEL DESCRIPTION}

The student information system parsed out students into the various $\mathrm{SCH}$ categories based on the predetermined groupings. These students were then tracked during the following Fall semester to determine student flow percentages. Within this study, student flow states are defined as:

1| students in credit hour group $j$ who stayed within that group,

2| students in credit hour group $j$ who moved to a different credit hour group,

$3 \mid$ students in other credit hour groups who moved to group $j$, and

4| students who were no longer enrolled at the institution.

Within this model, the following terms and symbols are used:

1| $n$ is the number of SCH levels in the model $(n=$ 24 for the 6-5CH groupings).

2) $h_{i j}$ is the ith Fall semester headcount for the $j$ th $\mathrm{SCH}$ level.

31 $H_{i}$ is the total undergraduate headcount for the ith semester.

4| $I_{i j}$ is the number of the $h_{i j}$ subset students not enrolled the next Fall semester.

5| $L_{i}$ is the total number of undergraduates enrolled in the ith Fall semester that are not enrolled in the $(i+1)$ th Fall semester.

6| $c_{i j}=h_{i j}-l_{i j}$ is number of continuing students in the jth $\mathrm{SCH}$ level.

7| $C_{i}$ is the total number of undergraduates that enrolled in the ith Fall semester that are also enrolled in the $(i+1)$ th Fall semester. 
8| $d_{i j k}$ is the number of the continuing $c_{i j}$ subset students that move from $\mathrm{SCH}$ level $j$ to $\mathrm{SCH}$ level $k$ from the ith Fall to the $(i+1)$ th Fall.

9| $w_{i j}$ is the number of the $C_{i}$ subset students that flow from all other levels into level $j$.

$10 \mid o_{i j}$ is the number of the $c_{i j}$ subset students that flow out of level $j$ into all other levels.

$11 \mid s_{(i+1) j}$ is the number of the new incoming students for the $(i+1)$ th Fall semester where $j$ is the $\mathrm{SCH}$ level.

12| $N_{(i+1)}$ is the total number of incoming new undergraduate students for the $(i+1)$ th semester.

With this terminology in place, the previously stated assumptions of the models can now be described algebraically:

1| When applying a model to a future period from Fall $(i+1)$ to Fall $(i+2)$, the total number of incoming students is assumed to be the same as it was for the period used to build the model, so it is assumed to have the value $N_{i+1}$. The fraction of new students by $\mathrm{SCH}$ level for that upcoming year is also assumed to be the same as it was in the period used to train the models, so each is assumed to be $s_{(i+1) j} / N_{i+1}$. Therefore, the estimated number of new students for a particular SCH level in that future year can be obtained by multiplying the value of this fraction by the estimated total number of students in the current year. That is, the estimate for the number of new students in the future year for that particular $\mathrm{SCH}$ level is given by $S_{(i+1) j} / N_{i+1} \times N_{i+1}=s_{(i+1) j^{*}}$

2| The fractional loss and fractional continuation ratios are also assumed to be fixed by $\mathrm{SCH}$ level. In other words, for a future year these ratios are assumed to be $I_{i j} / h_{i j}$ and $c_{i j} / h_{i j^{\prime}}$ the same as they were in the year used to build the model. Therefore, for the upcoming future period from Fall $(i+1)$ to Fall $(i+2)$, the estimated number of lost and continuing students for the jth $\mathrm{SCH}$ level are obtained by multiplying these ratios by the number of students $h_{(i+1) j}$ in that SCH level in the current Fall (i+1). This multiplication is $I_{i j} / h_{i j}$ $\times h_{(i+1) j}$ to estimate lost students in the jth $\mathrm{SCH}$ level and $c_{i j} / h_{i j} \times h_{(i+1) j}$ to estimate continuing students in the jth $\mathrm{SCH}$ level.

3| Finally, the fractional flow from a particular SCH level to another $\mathrm{SCH}$ level is assumed to be fixed. In other words, for a future year these ratios are assumed to be $d_{i j k} / c_{i j^{\prime}}$ the same as they were in the year used to build the model. Therefore, for the upcoming future period from Fall $(i+1)$ to Fall $(i+2)$, the estimated number of students transitioning from SCH level $j$ to $\mathrm{SCH}$ level $k$ is given by the value of this ratio $d_{i j k} / C_{i j}$ multiplied by the estimated number of continuing students in the jth $\mathrm{SCH}$ level.

The processes described above can be applied iteratively to obtain estimates for years even farther into the future by using the estimated values from one iteration as inputs into the next iteration.

Using the terms and formulae, we created a spreadsheet matrix (Table 1) that includes the various credit hour classifications as well as the nonabsorbed transient student states and the absorbed state of no longer enrolled. 


\section{Table 1. Basic Structure Matrix of the Markov Chain Model}

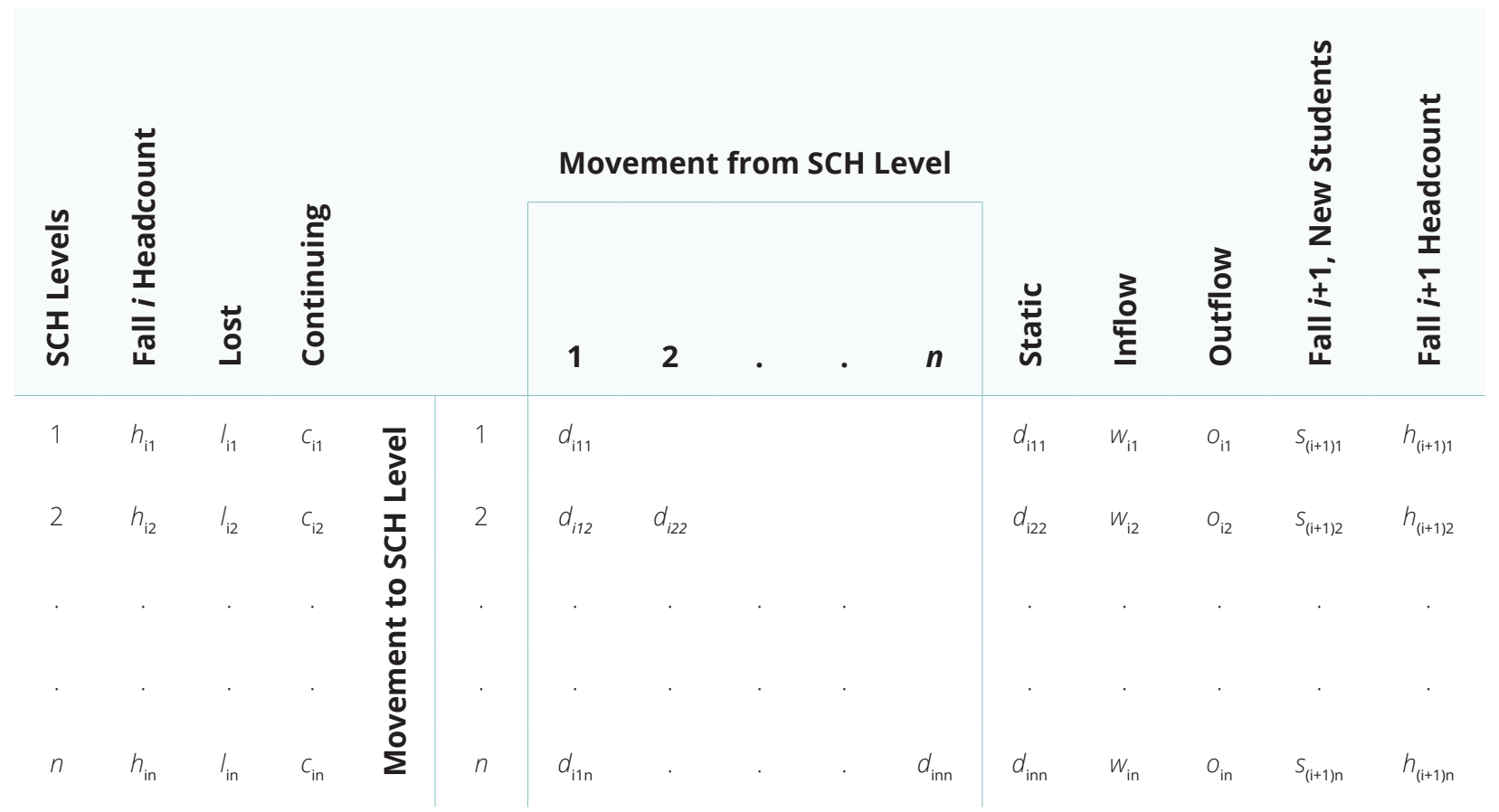

Note: This table shows the basic structure matrix of the headcount SCH flow associated with the Markov chain model that connects the undergraduate headcount in the ith Fall to the headcount in the $(i+1)$ th Fall.

From this $\mathrm{SCH}$ flow structure, we can observe the relationships of credit hour flow between and among the various states, including flow into nonabsorbing states (staying or moving into another credit hour state) or into absorbing states (not enrolling at the institution). The relationships among the variables are as follows:

1| $\quad c_{i j}=\sum_{k=1}^{n} d_{i j k}$ represents those current students who were in $\mathrm{SCH}$ level $j$ who stayed at the institution.

2| $\quad O_{i j}=\sum_{\substack{k=1 \\ k \neq j}}^{n} d_{i j k}$ represents those current students who were in SCH level $j$ who moved to all other SCH levels.

3| $w_{i k}=\sum_{\substack{j=1 \\ j \neq k}}^{n} d_{i j k}$ represents those current students who were in $\mathrm{SCH}$ levels other than $k$ who moved to SCH level $k$.
4| $H_{i}=\sum_{j=1}^{n} h_{i j}$ represents semester headcount at Fall semester $i$.

5| $L_{i}=\sum_{j=1}^{n} I_{i j}$ represents those students at Fall semester $i$ who did not reenroll.

6| $C_{i}=\sum_{j=1}^{n} C_{i j}$ represents those students at Fall semester $i$ who did reenroll.

The following relationship,

$$
\sum_{k=1}^{n} W_{i k}=\sum_{j=1}^{n} o_{i j}
$$

shows two equivalent ways of expressing the collection of students who remain at the institution and move from any $\mathrm{SCH}$ level to a different $\mathrm{SCH}$ level during the year. Conservation of student flow is obtained only when students from level $j$ stay in $\mathrm{SCH}$ 
Table 2. Annual Enrollment Data, Fall 2010-Fall 2017

\begin{tabular}{|c|c|c|c|c|c|}
\hline Fall $i$ & $\begin{array}{c}\text { Fall } i \\
\text { Headcount }\end{array}$ & Lost & Continuing & New & $\begin{array}{l}\text { Fall }(i+1) \\
\text { Headcount }\end{array}$ \\
\hline Fall 2010 & 9,652 & 3,773 & 5,879 & 3,957 & 9,836 \\
\hline Fall 2011 & 9,836 & 4,082 & 5,754 & 3,721 & 9,475 \\
\hline Fall 2012 & 9,475 & 3,965 & 5,510 & 3,761 & 9,271 \\
\hline Fall 2013 & 9,271 & 3,843 & 5,428 & 3,574 & 9,002 \\
\hline Fall 2014 & 9,002 & 3,685 & 5,317 & 3,598 & 8,915 \\
\hline Fall 2015 & 8,915 & 3,792 & 5,123 & 3,993 & 9,116 \\
\hline Fall 2016 & 9,116 & 3,945 & 5,171 & 3,919 & 9,090 \\
\hline Fall 2017 & 9,090 & not known & not known & not known & not known \\
\hline \multicolumn{3}{|c|}{$\begin{array}{l}\text { Given these relationships, the number of } \\
\text { undergraduates by level in the second Fall semester } \\
\text { can be calculated using the following formula: }\end{array}$} & \multicolumn{3}{|c|}{$\begin{array}{l}\text { The model used actual data from a Southeastern, } \\
\text { masters-level (Large Programs) public institution } \\
\text { for Fall } 2010 \text { through Fall 2017. The enrollments for } \\
\text { these } 8 \text { years are displayed in Table } 2 \text {. }\end{array}$} \\
\hline \multicolumn{3}{|c|}{$h_{(i+1) j}=h_{i j}-\ell_{i j}-o_{i j}+w_{i j}+S_{(i+1) j}$} & \multicolumn{3}{|c|}{$\begin{array}{l}\text { In developing the Markov chain matrix for each year, } \\
\text { the total number of students within each category }\end{array}$} \\
\hline \multicolumn{3}{|c|}{ This is the number of total transient students in } & \multirow{5}{*}{\multicolumn{3}{|c|}{$\begin{array}{l}\text { were noted and tracked to the following year. Within } \\
\text { this matrix, one can observe the various student } \\
\text { states by each category to determine who is moving } \\
\text { into transitional (nonabsorbing) states and who is } \\
\text { graduating or not returning. These more-granular } \\
\text { data within the matrix offer clues as to when }\end{array}$}} \\
\hline \multicolumn{3}{|c|}{ one of the $\mathrm{SCH}$ levels after 1 year who were not } & & & \\
\hline \multirow{2}{*}{\multicolumn{3}{|c|}{$\begin{array}{l}\text { absorbed by withdrawing or graduating. Therefore, } \\
\text { the total number of students in the }(i+1) \text { th Fall }\end{array}$}} & & & \\
\hline & & & & & \\
\hline \multicolumn{3}{|c|}{ semester is simply given by } & & & \\
\hline since the & ${ }_{i+1}=H_{i}-L_{i}-N_{i+1}$ & & \multicolumn{3}{|c|}{$\begin{array}{l}\text { students may be leaving the institution and where } \\
\text { there are potential bulges in the system coming } \\
\text { from new or transfer students. }\end{array}$} \\
\hline
\end{tabular}




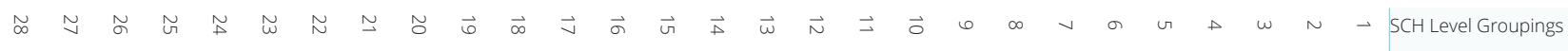

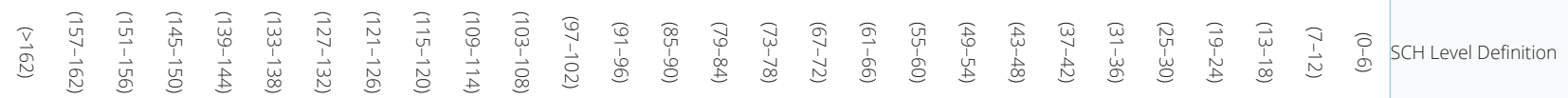

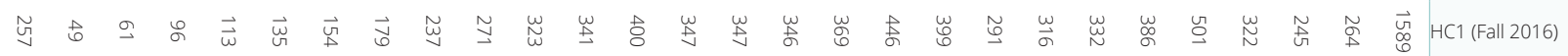

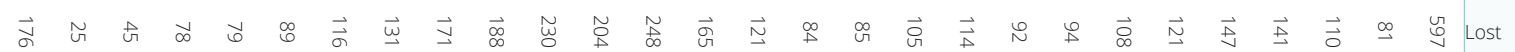

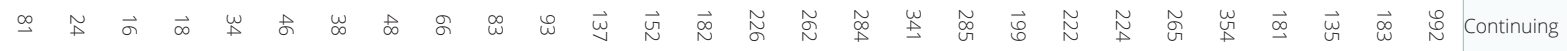

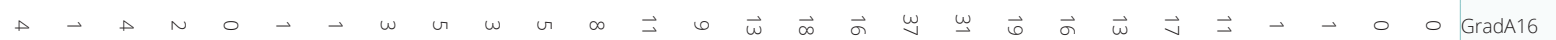

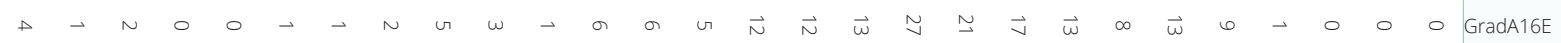

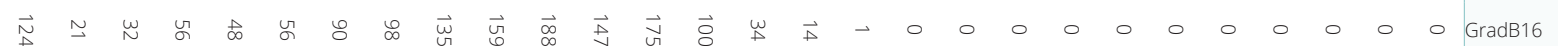

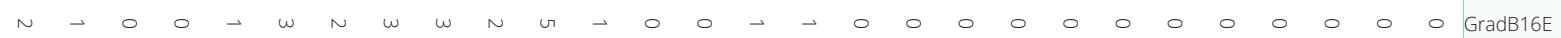
Movement to SCH Level Number

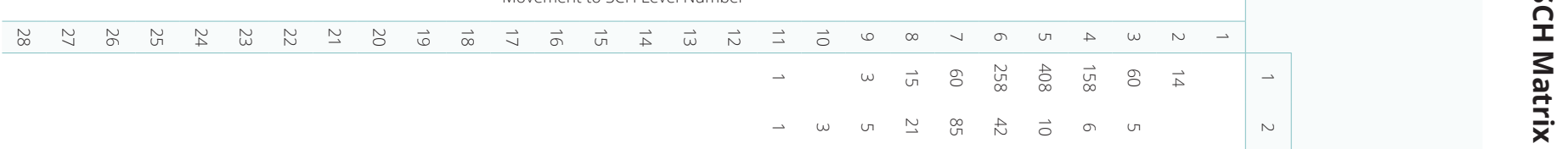

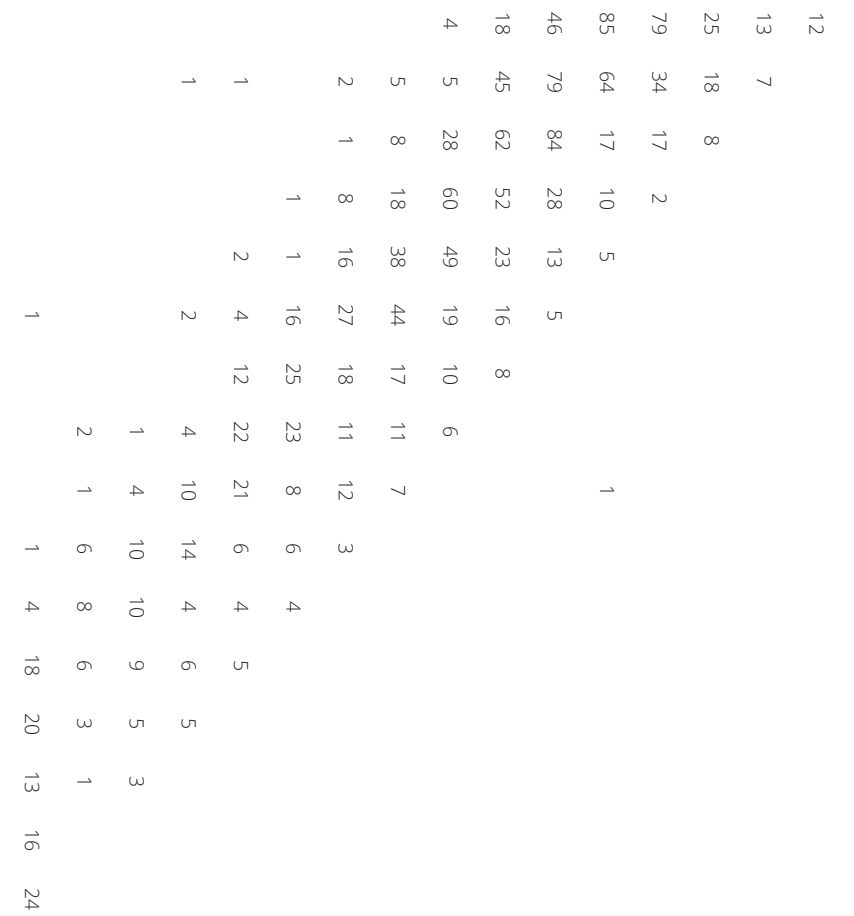


Table 3 represents one such matrix, the 6-SCH matrix from Fall 2016 to Fall 2017. The 28 6-SCH groupings are labeled down the left with the same corresponding 28 groupings across the center of the matrix. This table also contains headcount by groupings, how many within each grouping did not return, how many graduated, and how many new students enrolled in Fall 2017 but not Fall 2016. Matrices such as this one can be examined to identify the aforementioned leaks and bulges in the enrollment pipeline.

The following labels are used in Table 3:

1| HC1 (Fall 2016): Fall 2016 census undergraduate enrollment excluding special groups.

2| Lost: Enrolled Fall 2016 but not in Fall 2017. This includes students that graduated without reenrolling, as a subset. When determining if the student returned in Fall 2017, only undergraduate students, excluding special groups, were considered.

3| Continuing: Enrolled in Fall 2016 and Fall 2017.

4| GradA16: Awarded an associate degree in Fall, Spring, or Summer of Academic Year 2016-17. Note that only one degree is counted per student to avoid double-counting, with bachelor's degrees given precedence over associate's degrees.

5| GradA16E: Awarded an associate's degree and enrolled in next Fall term in another degree program. These students are a subset of GradA16.

6| GradB16: Awarded a bachelor's degree in Fall, Spring, or Summer of Academic Year 2016-17.

7| GradB16E: Awarded a bachelor's degree and enrolled in next Fall term in another degree program. These students are a subset of GradB16.
8| Columns in the center indicate movement of continuing students from the Fall 2016 SCH categories to the Fall 2017 SCH categories. Note that the central portion of Table 3 does not include counts for students who enrolled both semesters but remained in the same SCH level; these counts are instead separately labeled Static.

9| Static: Enrolled in Fall 2016 and Fall 2017 and stayed in the same SCH level.

10| Inflow to: Enrolled in Fall 2016 within a different $\mathrm{SCH}$ level but moved to the current SCH level in Fall 2017.

11 Outflow from: Enrolled in the SCH level during Fall 2016 but moved to another SCH level in Fall 2017.

12| New: Enrolled in Fall 2017 but did not enroll in Fall 2016. (NewUnder30Hrs and Transfer are subsets of New.)

13| NewUnder30Hrs: New students with fewer than 30 hours.

14| Transfer: Transfer students.

15| HC2: Fall 2017 census undergraduate enrollment excluding special groups.

According to the table, in Fall 2016 there were 1,589 students in the (0-6) SCH group. Out of these, 597 did not return the next Fall semester. A total of 408 of these students transitioned into the (25-30) $\mathrm{SCH}$ group, indicating that they were progressing normally, while 232 transitioned into groups of 24 or fewer $\mathrm{SCH}$. With a quick examination of the flow, it is easy to see that the majority of students are not returning within the $\mathrm{SCH}$ groupings that make up the freshman and sophomore years as denoted in the Lost column. In the (85-90) SCH grouping, 109 students graduated, and 5 of the students who graduated reenrolled in Fall 2017, meaning 
Table 4. Actual Enrollment and Predictions, Fall 2012-Fall 2017

\begin{tabular}{|c|c|c|c|c|c|c|c|}
\hline Model & & Fall 12 & Fall 13 & Fall 14 & Fall 15 & Fall 16 & Fall 17 \\
\hline Reality & Actual Headcounts & 9,475 & 9,271 & 9,002 & 8,915 & 9,116 & 9,090 \\
\hline \multirow[t]{2}{*}{ Model 10_11 6SCH } & Predicted Headcounts & 9,948 & 9,999 & 10,002 & & & \\
\hline & \% Diff. from Actual & $4.99 \%$ & $7.85 \%$ & $11.11 \%$ & & & \\
\hline \multirow[t]{2}{*}{ Model 11_12 6SCH } & Predicted Headcounts & & 9,244 & 9,076 & 8,958 & & \\
\hline & \% Diff. from Actual & & $-0.29 \%$ & $0.82 \%$ & $0.48 \%$ & & \\
\hline \multirow[t]{2}{*}{ Model 12_13 6SCH } & Predicted Headcounts & & & 9,105 & 8,980 & 8,903 & \\
\hline & \% Diff. from Actual & & & $1.14 \%$ & $0.73 \%$ & $-2.34 \%$ & \\
\hline \multirow[t]{2}{*}{ Model 13_14 6SCH } & Predicted Headcounts & & & & 8,839 & 8,745 & 8,694 \\
\hline & $\%$ Diff. from Actual & & & & $-0.85 \%$ & $-4.07 \%$ & $-4.36 \%$ \\
\hline \multirow[t]{2}{*}{ Model 14_15 6SCH } & Predicted Headcounts & & & & & 8,874 & 8,865 \\
\hline & \% Diff. from Actual & & & & & $-2.65 \%$ & $-2.48 \%$ \\
\hline \multirow[t]{2}{*}{ Model 15_16 6SCH } & Predicted Headcounts & & & & & & 9,258 \\
\hline & \% Diff. from Actual & & & & & & $1.85 \%$ \\
\hline
\end{tabular}

Note: The model creates predictions for the next 3 years (when actual data are available for comparison) for each of the models using the 6-SCH methods.

that 104 of the students who graduated did not reenroll. A total of 165 students in the (85-90) SCH grouping were lost (did not reenroll); subtracting the aforementioned 104 students leaves 61 students who neither graduated nor reenrolled.

A total of 914 new transfer students entered for Fall 2017, indicating a significant number of students who took some type of transfer credit. Many of these new transfers could constitute dual-enrolled students who took both high school and college classes. The bulk of the new transfer students, however, are entering with more than 54 and fewer than 84 SCHs.

In observing the higher groupings, the table indicates that 865 students had accumulated more than $126 \mathrm{SCH}$ and 448 (52\%) graduated. Of the students who earned more than 126 SCHs, 608 did not reenroll in the institution.

While this table represents only one of the six matrices created for this study, the possibilities of tracking student flow by groupings, classifications, or years are numerous. Moreover, it can be argued that the process of tracking student flow through transitional states within the Markov process is somewhat intuitive and indicative of the strong predictive properties of the model.

Table 4 shows the predictions for the next 3 years, along with the actual data. The model was built using the flow of students over a particular academic year. There were six such academic years used for 
construction of the models. The columns of Table 4 show the years for which an enrollment prediction was generated. As can be seen in the table, predictions for the 10_11 Model for both methods were overspecified by about 5\% for Fall 2012 and about 11\% for Fall 2014. The 11_12 Models produced better projections, coming within less than $1 \%$ of the actual values for all 3 years. The prediction of the 12_13 Model differed from the actual enrollment by an average of $-0.2 \%$. Results from the 13_14 Model indicate that the prediction differed by an average of $3.1 \%$. In most cases, predictions farther into the future from the years used to train the models have greater residuals, which is to be expected in any forecasting problem.

We calculated averages of the absolute values of the percentage differences between the actual and predicted values for enrollment using the actual and predicted enrollment from Table 4. The percentage difference between the predicted and actual value is defined as

$\%$ difference $=\frac{\text { predicted value }- \text { actual value }}{\text { actual value }} \times 100 \%$

We can examine the predictive ability of the models by using the average value of the absolute values of these percentage differences, because these values show on average how far off the models were, regardless of sign. In a mathematical sense, the absolute value between two numbers is known as the standard Euclidean distance between two points and indicates the real distance between two numbers (Bartle \& Sherbert, 2011). The results as shown in Table 5 clearly indicate that the predictive ability of the model decreases as number of years out from the years used to build the model increases, which is expected, similar to how weather forecasts become less accurate the farther they go into the future.

\section{Table 5. Mean Absolute Value of Percent Differences by Years Out for 6-SCH Models}

\begin{tabular}{ll}
$\begin{array}{l}\text { Prediction } \\
\text { Time Frame }\end{array}$ & $\begin{array}{l}\text { Mean Absolute Value of } \\
\text { Percent Difference }\end{array}$ \\
\hline $\mathbf{1}$ year out & $1.96 \%$ \\
\hline $\mathbf{2}$ years out & $3.19 \%$ \\
\hline $\mathbf{3}$ years out & $4.57 \%$ \\
\hline
\end{tabular}

Based on the results from Table 5, the study will examine only 1 -year-out predictions, because these were the most accurate. The actual values are compared with those 1-year-out predictions in Table 6. The predicted enrollment for Fall X in Table 6 is produced from the enrollment data from Fall X-2 and Fall X-1 and subsequent flow rates from Fall X-2 to Fall X-1.

Note that the 6-year average of the absolute values of the percentage differences by class range from $2.8 \%$ to $4.7 \%$. The 2016 freshman percent difference of $-12.9 \%$ represents an outlier due to a major university initiative to increase new freshmen enrollment. This influx of new freshmen was significantly different from past years and clearly signals the bulge in the student flow pipeline as mentioned above. By utilizing the iterative process of producing Fall X projections from the enrollment data from Fall $X-2$ and subsequent flow rates from Fall $X-2$ to Fall $X-1$, the effect of this bulge in the system can be tracked into the future to plan upcoming course offerings. 
Table 6. The 6-SCH Models' 1-Year-Out Predictions Compared to Actual Enrollment, 2012-17

\begin{tabular}{|c|c|c|c|c|c|c|c|}
\hline & & Freshman & Sophomore & Juniors & Seniors & All Levels & $\begin{array}{l}\text { Mean Absolute } \\
\% \text { Difference of } \\
\text { Class Levels }\end{array}$ \\
\hline \multirow[t]{3}{*}{2012} & Actual & 2,876 & 2,035 & 1,871 & 2,693 & 9,475 & \\
\hline & Predicted & 3,114 & 2,090 & 1,966 & 2,778 & 9,948 & \\
\hline & \% Difference & $8.28 \%$ & $2.68 \%$ & $5.10 \%$ & $3.17 \%$ & $5.00 \%$ & $4.81 \%$ \\
\hline \multirow[t]{3}{*}{2013} & Actual & 2,729 & 1,890 & 1,870 & 2,782 & 9,271 & \\
\hline & Predicted & 2,817 & 1,875 & 1,834 & 2,718 & 9,244 & \\
\hline & \% Difference & $3.23 \%$ & $-0.79 \%$ & $-1.92 \%$ & $-2.30 \%$ & $-0.29 \%$ & $2.06 \%$ \\
\hline \multirow[t]{3}{*}{2014} & Actual & 2,644 & 1,803 & 1,870 & 2,685 & 9,002 & \\
\hline & Predicted & 2,709 & 1,800 & 1,789 & 2,807 & 9,105 & \\
\hline & \% Difference & $2.47 \%$ & $-0.16 \%$ & $-4.36 \%$ & $4.53 \%$ & $1.14 \%$ & $2.88 \%$ \\
\hline \multirow[t]{3}{*}{2015} & Actual & 2,533 & 1,944 & 1,738 & 2,700 & 8,915 & \\
\hline & Predicted & 2,574 & 1,809 & 1,816 & 2,640 & 8,839 & \\
\hline & \% Difference & $1.60 \%$ & $-6.93 \%$ & $4.51 \%$ & $-2.24 \%$ & $-0.85 \%$ & $3.82 \%$ \\
\hline \multirow[t]{3}{*}{2016} & Actual & 2,921 & 1,724 & 1,855 & 2,616 & 9,116 & \\
\hline & Predicted & 2,543 & 1,885 & 1,801 & 2,644 & 8,874 & \\
\hline & \% Difference & $-12.93 \%$ & $9.36 \%$ & $-2.89 \%$ & $1.07 \%$ & $-2.65 \%$ & $6.56 \%$ \\
\hline \multirow[t]{4}{*}{2017} & Actual & 3,048 & 1,829 & 1,652 & 2,561 & 9,090 & \\
\hline & Predicted & 3,053 & 1,788 & 1,766 & 2,651 & 9,258 & \\
\hline & \% Difference & $0.17 \%$ & $-2.24 \%$ & $6.91 \%$ & $3.51 \%$ & $1.85 \%$ & $3.21 \%$ \\
\hline & $\begin{array}{l}\text { Mean Absolute } \\
\% \text { Difference }\end{array}$ & $4.78 \%$ & $3.69 \%$ & $4.28 \%$ & $2.80 \%$ & $1.96 \%$ & \\
\hline
\end{tabular}

By observing the predictive capabilities of the model, it is easy to see how administrators and enrollment managers can use these results to plan for classes and instructional personnel. Here, both annual projections and classification average projections for the 5-year period were off by no more than 6.6\%, which should fall within the margin of error for most larger institutions.

Furthermore, Monte Carlo simulation could be used to obtain enrollment predictions that give a range of plausible values instead of a single point estimate for a future year's enrollment. Monte Carlo simulations have been used in the context of higher education by Torres, Crichigno, and Sanchez (2018) to examine degree plans for potential bottlenecks. In applying these methods to this enrollment model, the fractions of students transitioning between specific levels would be treated more like the result of many coin flips than as fixed fractional values, and the ranges of predicted values could be obtained by repeated random simulation. This level of simulation was not performed in this study. 


\section{GONGLUSIONS}

The use of Markov chains in projecting enrollment and the management thereof has gained popularity among professionals in higher education. The short-term projections created by this stochastic process are unique to other time-tested forecasting tools used in enrollment management. When used properly, Markov chains can aid institutions in determining progression of students that are different from more-traditional ARIMA and regression prediction tools in that:

1| they can give accurate enrollment predictions with only 2 previous years' data, which can be helpful when large longitudinal databases are not available;

2| they can be used to generate predictions on segments of a group of students rather than the entire population, which may be required for other models; and

3| the almost intuitive nature of the Markov chain lends well to changes in student flow characteristics, which often cannot be explained by a complex statistical formula.

By creating groupings and tracking students within those groupings by the state they transition into, the researcher can also get a better picture of what type of students are leaving and when they are leaving.

As shown in this study, the strong predictability of Markov chains allows administrators to better plan course scheduling and instructor demand while managing tight budgets. In this study, several predictive headcount models were developed using $\mathrm{SCH}$ flow as the annual driver. Eight years of Fall enrollment data from the institution were used to develop the models. When applied to historical data each gives 1 -year-out predictions within a calculated level of uncertainty. The models can easily be modified to change the new student input data, the continuation rates, and the interlevel flow rates, should that be desired. Furthermore, similar models could be used to track Fall to Spring retention as well as Spring to Fall retention.

\section{REFERENCES}

Bartle, R. G., \& Sherbert, D. R. (2011). Introduction to real analysis. Urbana-Champaign: University of Illinois.

Borden, V. M. H., \& Dalphin J. F. (1998). Simulating the effect of student profile changes on retention and graduation rates: A Markov chain analysis. Paper presented at the Annual Forum of the Association for Institutional Research, Jacksonville, FL, May 19.

Brezavšček, A., Bach, M., \& Baggia, A. (2017). Markov analysis of students' performance and academic progress in higher education. Organizacija, 50(2), 83-95.

Clagett, C. A. (1991). Institutional research: The key to successful enrollment management. Office of Institutional Research. Largo, MD: Prince George's Community College.

Coomes, M. D. (2000). The historical roots of enrollment management. In M. D. Coomes (Ed.), The role student aid plays in enrollment management: New directions for student services, 89 (5-18). San Francisco: Jossey-Bass.

Day, J. H. (1997). Enrollment forecasting and revenue implications for private colleges and universities. In D. T. Layzell (Ed.), Forecasting and managing enrollment and revenue: An overview of current trends, issues, and methods: New directions for institutional research, 93 (51-65). San Francisco: Jossey-Bass. 
Ewell, P. T. (1985). Recruitment, retention and student flow: A comprehensive approach to enrollment management. National Center for Higher Education Management Systems, Monograph 7, Boulder, CO.

Fallows, J., \& Ganeshananthan, V. (2004, October). The big picture. The Atlantic. https://www. theatlantic.com/magazine/archive/2004/10/the-bigpicture/303520/

Gagne, L. (2015). Modeling the progress and retention of international students using Markov chains. Honors Research Projects 3, University of Akron, Akron, $\mathrm{OH}$.

Herron, J. (1988). Universities and the myth of cultural decline. Detroit, MI: Wayne State University Press.

Hopkins, D. S. P., \& Massy, W. F. (1981). Planning models for higher education. Stanford, CA: Stanford University Press.

Hossler, D. (1984). Enrollment management: An integrated approach. New York: College Board.

Johnson, A. L. (2000). The evolution of enrollment management: A historical perspective. Journal of College Admission, 166, 4-11.

Liljegren, A., \& Saks, M. (Eds.). (2017). Professions and metaphors: Understanding professions in society. New York: Routledge, Taylor \& Francis Group.

Luna, A. (1999). Using a matrix model for enrollment management. Planning for Higher Education, 27(3), 19-31.
Oliver, R. M. (1968). Models for predicting gross enrollments at the University of California. Ford Foundation Program for Research in University Administration, Berkeley, CA.

Pierre, C., \& Silver, C. (2016). Using a Markov chain model to understand the behavior of student retention. In N. Callaos, H. Chu, J. Ferrer, S. Fernandes, \& B. Belkis Sánchez (Eds.), The 7th International Multi-Conference on Complexity, Informatics, and Cybernetics/The 7th International Conference on Society and Information Technologies: Proceedings (pp. 248-251). Winter Garden, FL: International Institute of Informatics and Systemics.

Seltzer, R. (2017, July 24). State funding cuts matter. Inside Higher Ed. https://www.insidehighered.com/ news/2017/07/24/new-study-attempts-show-howmuch-state-funding-cuts-push-tuition

Torraco, R. J., \& Hamilton, D. W. (2013). The leaking U.S. educational pipeline and its implications for the future. Community College Journal of Research and Practice, 37(3), 237-241.

Torres, D., Crichigno, J., \& Sanchez, C. (2018). Assessing curriculum efficiency through Monte Carlo simulation. Journal of College Student Retention: Research, Theory \& Practice. https://doi. org/10.1177/1521025118776618 